\title{
NOTAS SOBRE LA IMPLANTACION DE LA VIDA RELIGIOSA MEDIEVAL EN EL TERRITORIO CASTELLANO-LEONES
}

\author{
Antonio Linage Conde \\ Correspondiente de la Real Academia de la Historia
}

Una cierta constante con la que ha de enfrentarse el historiador de la Iglesia Católica es la necesidad de tener en cuenta dos coordenadas de su argumento investigador, a saber, la universal y la local. La primera, por lo ambicioso y desconocedor de fronteras de la vocación religiosa de aquélla; la segunda, por la forzosa influencia en cada caso del medio ambiente. $Y$ por supuesto que la tendencia de la primera a la uniformidad se ha ido acusando más y más desde los orígenes hasta la centralización romana, que alcanzó su más alta cúspide en el Concilio Vaticano I de 1870. Concretamente, en el ámbito que hoy nos preocupa, si en el alto miedievo monástico es'el entorno inmediato del país el que da la nota, en el bajo medievo frailuno se acusa con mucha más intensidad el de la ecumene eclesial.

Esto por un lado y en términos muy genéricos.

Que teniendo ya en cuenta exclusivamente los específicos nuestros se nos complica la situación, de una parte por lo que de diferenciada tiene la Edad Media peninsular, con su endémica problemática de la Reconquista y la Repoblación; y de otra, por la impronta aún más demandador de expansiva universalidad llevada consigo en el tema de la vida regular consagrada.

Diferenciación aquélla que, sin embargo, no dispensa de la atención obligada al dicho factor común siempre presente, aunque requiera un conocimiento de la calendada doble dimensión más difícil de conseguir 
que allende los Pirineos, donde la distorsión no suele ser tan particularista. Como que esa exigencia es la que ha separado demasiado en buen número de casos la investigación de la historia monástica hispana de la del resto del oeste europeo, siendo tanto más notables los estudiosos que han acertado a sobreponerse a ella, tal el portugués José Mattoso.

Por este camino, si se nos permite, un recuerdo personal. Hace poco teníamos ocasión de oír una apología de la historia de Castilla cual inspiradora y determinante de la empresa fundacional de la Orden de Predicadores por Santo Domingo de Caleruega o de Guzmán, prescindiendo, como si de algo sobrevenido y accesorio se tratara, de su gestación y alumbramiento ultrapirenaicos. Eso en un extremo. Que en otro se ha llegado a postular por algún ensayista reputado la índole “más bien» francesa de San Ignacio de Loyola como explicativa de ciertas características de su paralela obra de la Compañía de Jesús.

Y todavía una observación liminar. En nuestro título hablamos de la implantación en nuestro país de la vida religiosa. $Y$ es el caso que la trascendencia de la materialidad concreta en cada caso de esta implantación es muy diversa a lo largo de la evolución de la vida religiosa misma que tiene lugar en la época que vamos a estudiar. Pues para la etapa ya benedictinizada, dentro del período monástico, la exigencia por la Regla de San Benito de la estabilidad del monje en el monasterio de su profesión (1) da una dimensión casi teológica a dicho monasterio, a la casa sin más. Y si en la etapa pre-benedictina la tal exigencia reglar no se daba, sin embargo las características esenciales de aquel monacato, colonizador, repoblador y campesino ante todo, le hacian tremendamente vinculado a la tierra (2). En cambio, la mentalidad y la actuación de los frailes bajomedievales es ya muy distinta. Lo que en ellos predomina es la familia religiosa unitaria. Habiendo sido precisamente lo movible de la nueva sociedad lo que más justificó su nacimiento y desarrollo. De ahí que sus casas sean más bien residencias mutables que otra cosa (3). Pero este detalle no nos debe hacer olvidar

(1) Regula Benedicti, sobre todo IV, 78 -officina vero ubi haec omnia diligenter operemur claustra sunt monasterii et stabilitas in congregatione-; y LVIII, 17 -suscipiendus autem, in oratorio coram omnibus, promittat de stabilitate sua.

(2) Aunque más adelante hayamos de reconocer que la necesidad de una cierta libertad espacial de movimientos, y no sólo la de una mayor autonomía de la voluntad individual, con vistas al aprovechamiento de las coyunturas del avance repoblador, le hicieron. también en atención a este capitulo de la estabilidad, un tanto incompatible con la Regla de San Benito.

(3) Aunque la permanencia de los grandes acabe en la práctica siendo la norma general. 
lo fecundo de su encarnación sociológica en una geografía determinada, aunque este último aspecto no implique una sede material tan concreta ni ésta alcance una valoración ideal tan intensa (4).

\section{El predominio del monacato en la repoblación (hasta el siglo XI)}

La vinculación de la implantación y difusión de la vida religiosa a la Reconquista y la Repoblación de los nuevos territorios incorporados a los estados cristianos peninsulares es algo que no necesita ser explicado. Y ello desde los comienzos de la monarquía astur hasta la absorción del reino de Granada (5).

Pero ello no quiere decir que no se den soluciones de continuidad en la evolución, tanto de las modalidades de los dichos lazos como de su trascendencia en el hacerse del país.

Trascendencia que alcanzó su cota máxima en la primera etapa, la de los tres primeros siglos, cuando el monacato llega hasta cierto punto a ser un agente repoblador decisivo (6), lo cual ha pasado ya a estar tan admitido en la historiografía por la cual nos movemos que hace superfluo su apuntalamiento con citas precisas. Es la fase «monacal» de la repoblación del valle del Duero (7) por monjes y hombres libres, según el epíteto con que prefirió caracterizarla Antonio Ubieto; la intensa influencia de los monjes inmigrados desde Al-Andalus al

Ahí está su recuerdo toponimico en el callejero de casi todas las ciudades de nuestra vieja Europa y de la América católica, por apelar sólo quizá al ejemplo más llamativo.

(4) Lo que no supone que la elección del emplazamiento de los conventos mendicantes en las ciudades carezca de significación histórica. Magnifico ejemplo de una aportación en este sentido el de ANGELA BEIRANTE, Santarem à chegada dos dominicanos, pendiente de publicación en las actas del ull Encontro sobre historia dominicanan de Santarem, 1982.

(5) Todavía teniendo el ejército de los Reyes Católicos sitiada Málaga, se presentaron al rey unos frailes de la nueva orden de los Minimos, de parte de su mismo fundador, San Francisco de Paula, pidiéndole su venia para fundar en su monarquía. Tomada la ciudad en 1487, una capilla edificada en el mismo campamento fue la primera sede peninsular de dichos religiosos a partir de 1493 .

(6) Moxó ha llamado la atención sobre lo determinante del papel monasterial, durante esta etapa, en la creación de la crudimentaria articulación administrativa que resultaba indispensable a la monarquía astur-leonesa" y no sólo en "la aparición de nuevas fuentes de riquezan (Repoblación y sociedad en la España cristiana medieval, Madrid, 1980, p. 59.

(7) Como la paralela del Pirineo. Lacarra ya hizo constar que utoda la cristiandad hispánica liberada se encontraba en circunstancias análogas». Entre las zonas de particular densidad que señala nos interesan aqul, sobre todo, el Bierzo, la que rodea la ciudad de León y la primitiva Castilla. 
Norte, despertadora del ideal restaurador goticista en los monarcas reconquistadores a partir de Alfonsoll, vista por Derek William Lo$\max (8)$; la simbolización que Jacques Fontaine ha hecho de «la alianza entre la reconquista militar y la repoblación monástica» en el levantamiento, junto a la línea defensiva del Arlanza, de la torre mozárabe del nuevo monasterio-infantado de los Santos Cosme y Damián fundado en Covarrubias el año 978 para Urraca, la nieta de Fernán González.

\section{La supervivencia pactual y la benedictinización tardia}

Al estudiar al detalle (9) la lenta y morosa difusión de la Regula Benedicti en los reinos cristianos de la Península, cuando ya aquélla había alcanzado categoría monopolizadora de la observancia monástica en la Europa católica, más que a una resistencia consciente nosotros nos inclinábamos a achacar tal particularidad arcaizante a una cierta marginación natural de la actualidad ultrapirenaica determinada en nuestra tierra por la diferente problemática siempre generada por el acuciamiento de la Reconquista y la Repoblación. $Y$ no es que nos hayamos retractado (10) ni vayamos a hacerlo ahora aquí.

Pero sí nos parece puesto en razón insistir en dos notas exigidas por la repoblación monástica de frontera y un poco incompatibles con el benedictinismo más ortodoxo, como vamos a hacerlo.

Ya hemos hablado antes de la exigencia benedictina de la estabilidad de los monjes en el monasterio de su profesión. En tanto que la ratio essendi de aquella repoblación estribaba en serlo de una tierra predestinada a irse corriendo hacia el Sur a medida que la frontera iba avanzando. Con lo que queda deducido que en su caso la estabilidad monástica sólo podía predicarse del país en sí, pero no de cada casa concreta. $Y$, sin embargo, paradójicamente, el monacato repoblador resultante, al irse asentando en sus nuevas sedes agrarias ganadas al yermo, acabó por quedar más ligado a la tierra que el benedictino más

(8) "Possible though not demonstrable»; The Reconquest of Spain (Londres, 1978), p. 29. Sobre el aporte material de los monjes mozárabes a la tarea repobladora, véase $\mathrm{J}$. PEREZ DE URBEL, Reconquista y Repoblación de Castilla y León durante los siglos IX y $X$, en el volumen colectivo "La Reconquista española y la Repoblación del pais» (Zaragoza, 1951), pp. 151-2 y 159-60.

(9) Los origenes del monacato benedictino en la Peninsula lberica (León, 1973).

(10) Véase nuestro artículo posterior, Tras las horas eruditas. Meditaciones en torno a la benedictinización hispana, en "Cistercium», 32 (1980), 421-40. 
consagrado en ciertos casos (11). Que «justamente por su mayor contacto con la tierra - lo ha advertido ya Lacarra - los monjes estaban mejor preparados que los obispos para esa labor restauradora".

Por otra parte, el impulso colonizador y su consiguiente movilidad inicial que queda apuntada, desde luego que había de verse favorecido por alguna liberalización de la obediencia cenobítica. Que la hora lo era la del individualismo emprendedor e insustituible incluso un poco también en aquella esfera sacra. $Y$ por eso se recurrió entonces a un recuerdo del monacato suevo-visigótico del Noroeste, la única de las particularidades hispanas (12) pre-islamitas dentro de la tradición monástica común, el pactualismo, sistema que sustituía por un acuerdo bilateral entre el abad y los monjes la ortodoxa inmolación incondicionada de la voluntad de los últimos al primero. Pactualismo, por supuesto, abiertamente incompatible con la Regla de San Benito (13) y que, desbordadas las fronteras de su expansión anterior al 711(14), en la repoblación castellana nos hace acto de presencia desde San Pedro de Tejada el año 855 hasta Santa Maria de Sotovellanos el año $1044(15)$.

(11) Son esos tan numerosos monasterios «pequeños, inestables, pobres, ligados a la tierra», de que nos ha hablado José Mattoso. Inestables en muchos casos por su escasa consistencia, pero no por falta de vocación de arraigo.

(12) Sus causas se han discutido. Debe desecharse la opinión que le atríbuía al germanismo, entre la psicología colectiva racial y la tradición literaria. Más bien hay que moverse, nos parece, entre esa hipertrofia contemporánea de un monacato abusivo, a la búsqueda de ventajas fiscales o de la liberación del control económico de los obispos (monasterios propios - clericales o no-y familiares, prohibidos por la Regula Communis), y el equilibrio entre la sumisión al abad y la jurisdicción episcopal - disciplinaria, no financiera-sobre el monacato común de entonces.

(13) Aunque no en mayor medida que con las de los mismos padres de la España visigoda, tales Isidoro y Fructuoso.

(14) Recientemente, su optimo conocedor Charles-Julian Bishko, ha reivindicado una mayor permanencia del fenómeno en su Galicia y Portugal septentrional originarios que la hasta ahora admitida; Portuguese pactual monasticism in the eleventh century: the case of Sáo Salvador de Vacariça, en "Estudos de História de Portugal», I (= «Homenagem a A. H. de Oliveira Marques», Lisboa, 1982, 129-54). En todo caso, esa permanencia pudo estar influida por su misma difusión en los otros territorios aun teniendo ésta lugar en función de una sociología distinta.

(15) Bibliografia en CH. J. BISHKO, Hispanic Monastic Pactualism: the controversy continues, en "Classical Foliam, 27 (1973), 173-85, y J. G. FREIRE y G. ROCCA, Patto, en "Dizionario degli istituti di perfezione», VI, coll. 1292-4. Estos autores llaman la atención sobre el peligro de identificar la palabra upactumn con una profesión pactual, siendo asi que esa es a veces sinónima nada más que de upropositum», o sea, de profesión ordinaria. Este ha sido el extremo concreto de nuestra discrepancia con Mattoso. Véase éste, L'introduction de la Règle de saint Benoît dans la Péninsule lbérique, en «Revue d'histoire ecclésiastique $\ldots$, 70 (1975), 731-42. 
Pero en esta última data ya estaba muy avanzado al norte del Duero, en definitiva al país de la repoblación ya consolidada, el proceso benedictinizante. Al país de la dicha consumación repobladora y que por lo mismo había dejado de ser teatro de la civilización de frontera. Cierto que la colonización siguió siendo una necesidad todavia durante mucho tiempo alli, y no tardaremos en ver algún ejemplo de su continuidad cenobítica. Pero se trataba de una colonización interior, no de una tarea perentoria para consolidar el avance de las fronteras de la cristiandad y el Estado. Lo cual implicaba también que la movilidad monástica no era fundacional sino de expansión del dominio territorial, latifundista si se nos permite simplificar, de los monasterios (16), y por ello carecía de sentido, desde ambas ópticas, la material y la espiritual, el individualismo de los monjes. Al contrario, era el trance de aunar los esfuerzos en la cohesión estable de las comunidades. A la vez que lo numeroso de algunas de éstas y la tranquilidad y permanencia ambientales favorecían los contactos con otras y habian elevado el nivel cultural (17). Y la conclusión no es difícil de sacar. Que la adopción de la Regula Benedicti era fruta madura.

Concretamente en el caso de Castilla, se explica así el foco librario difusor de la misma, en conexión con el riojano (18), que la codicología nos ha permitido seguir con un genuino apasionamiento. Es el de Silos,

(16) Tema al que se vienen dedicando en los últimos lustros monografías de interés, aunque a menudo no demasiado conocedoras de los monasterios en sí. Más escasas resultan las fuentes para el estudio socioeconómico de los pequeños monasterios anteriores, ni siquiera en conjunto.

(17) Para darse cuenta de la fecundidad, no por callada menos jugosa y abundosa, de estos contactos culturales, puede verse M. C. DIAZ Y DIAZ, El cultivo del latín en el siglo $X$, en "Anuario de estudios filológicos", 4, 1981, 72-81. Aunque su estudio sea de la lengua, escribe su autor (p. 78), cómo "puede añadirse una información todavía más significativa para valorar el conocimiento que del latín tiene nuestro personaje. Todo parece indicar que Vigilán y sus colaboradores son los responsables de la selección y ordenación de los materiales que contiene el Códice Albeldense que, en buena parte, debían coincidir con los contenidos en el manuscrito perdido de $980 \%$, selección y ordenación de interés para la benedictinización como creemos haber demostrado en otro lugar.

(18) Un botón de muestra de la intensidad de estos contactos riojano-castellanos es la única regla monástica compuesta en la Península durante el alto medievo post-visigótico. Se trata de una adaptación de la de San Benito para una comunidad de monjas de rito hispánico. $Y$ uno de sus dos capítulos independientes del texto benedictino está tomado del penitencial añadido al manuscrito de los Comentarios de Esmaragdo a la Regula Benedicti copiado en Silos el año 945. Véanse A. LINAGE CONDE, Una regla monástica riojana del siglo X: el rLibellus a Regula Sancti Benedictio subtractus (Salamanca, 1972); y A. DE VOGUE, "Libellus a Regula Sancti Benedicti subtractus", en el «Dizionario" citado en la nota $15, V$, coll. $940-2$. 
Cardeña, Arlanza y Valeránica o Berlangas. Y por poner un ejemplo del extremo leonés, la labor aún precursora del santo obispo de Astorga, Genadio, restaurador de San Pedro de Montes y fundador de Santiago de Peñalba.

Y esta cronología nos ha acercado a Cluny. Que desde luego hemos de mencionar, pero con una brevedad que por supuesto puede parecer insólita si nos fijamos en la enorme influencia que en la monarquía castellano-leonesa ejerció, difícilmente comparable en los ámbitos político y cultural a la de ningún otro monasterio en territorio al menos occidental alguno (19). Mas precisamente por eso la parsimonia de nuestro tratamiento. Porque tal impronta fue de abrumador predominio extramonástico (20), y cuando es monástica incluso, recae muy secundariamente en los ámbitos que ahora nos interesan, de la fundación de nuevas casas, ni siquiera de la sumisión jurídica de las antiguas. Concretándose esa su geografía dentro de los territorios que nos están ocupando en las tierras de Campos de la diócesis palentina y en algunos puntos del camino de Santiago, que desde luego no obsesionó a la abadía borgoñona como luego lo haría con los canónigos regulares: San Isidoro de Dueñas, San Zoil de Carrión de los Condes, las ermitas de Cerrato y Santa Coloma de Burgos (21).

Dentro de la esfera específica cenobítica la presencia cluniacense

(19) Véase una síntesis en nuestro trabajo El impacto de Cluny en la historia española, pendiente de publicación en las actas del congreso "L'Italia nel quadro dell'espansione europea del monachesimo cluniacense" (Pescia, 1981). Sigue siendo fundamental el de $\mathrm{CH}$. J. BISHKO, Fernando / y los origenes de la alianza castellano-leonesa con Cluny, en «Cuadernos de Historia de Españan, 47-8 (1968-9), 31-135 y 50-116. Para la implantación, F. FITA, La provincia cluniacense de España, en «Boletín de la Real Academia de la Historia", 20 (1892), 431-52. Bibliografia abundante sobre este tema y el resto de los de esta comunicación en nuestra colaboración a la uHistoria de la Iglesia en España dirigida por Ricardo Garcia Villoslada", II, $1^{\circ}$ y $2^{\circ}$ (Madrid, 1982), pp. 141-91, 339-48, 352-401 y 403-26; y 117-60, respectivamente.

(20) Como que llegó a trascender al futuro dinástico de nuestros territorios. Véase CH. J. BISHKO, Count Henrique of Portugal, Cluny, and the antecedents of the Pacto Succesorio, en "Revista portuguesa de história", 13, 1971, 155-88.

(21) Para el supuesto caso de la reforma cluniacense de Oña por Sancho el Mayor, véase F. J. FACI LACASTA, Sancho el Mayor de Navarra y el monasterio de San Salvador de Oña, en «Hispania», 37, 1977, 299-317. Atribuye su falsificación a una insistencia feudalizante en el siglo XII, llamando la atención sobre la feudalización de Castilla durante aquel reinado y la circunstancia de haber nacido Castilla del llamado por Moxó uprincipio feudal». Piensa que durante dicho período navarro Ona fue un centro nostálgico del nacionalismo castellano. Al citar mis trabajos sobre la benedictinización me achaca haber identificado lo benedictino y lo cluniacense, lo que él por su parte hace y yo, desde luego, no estimo exacto. 
acabó dando el espaldarazo a la benedictinización. Si bien parece que por la fuerza misma de las cosas. Aunque la falta de entusiasmo suyo a ese propósito pudo también deberse a no ser ya necesario en aquella coyuntura (22).

\section{La etapa concejil entre Duero y Tajo. El Císter}

Salta a la vista que la repoblación al sur del Duero es ya la de los municipios de derecho privilegiado, no sólo incompatibles con la hipertrofia monástica, sino desconfiados hacia todo lo eclesiástico como propenso a la intromisión de la cuña señorial. Que en ese sentido las cautelas del Fuero de Sepúlveda (23) hacia los "cogolludos" no son un ejemplo aislado, sino un síntoma común.

Aun así, en pleno territorio concejil, se dan enclaves cenobíticos, tal el del priorato silense de San Frutos, en tierras sepulvedanas, en virtud de una donación de Alfonso VI del terreno de su futura sede, fechada el mismo año, 1076, que el citado fuero de la villa (24). ¿Política regia a la búsqueda de algún equilibrio (25)? No creemos pecar de demasiado sutiles al sospecharlo (26).

(22) Para la polémica ideológica entre lo castellano y lo leonés (mejor para sus sendas interpretaciones de hoy), a propósito de la cual tanto se ha valorado el detalle de la recepción benedictina, si bien inexactamente visto, es una nueva aportación la de D. W. LOMAX, Catalans in the Leonese Empire, en «Bulletin of Hispanic Studiesw, 59, 1982, 191-7 (sobre todo, p. 193). En todo caso hay que tener en cuenta que entonces si se da en León una resistencia nostálgicamente visigotista y arcaizante contra lo benedictino (Coyanza, traslado de los restos de San Isidoro, etc.) como coletazo reaccionario consciente, y no antes, donde no se concebía un supuesto apego a lo visigótico que en sí nada antibenedictino era, aunque pudiera matizarse (así entre las reglas de isidoro y Fructuoso).

(23) Como síntoma vale, aunque se trata del extenso posterior.

(24) Véase nuestro trabajo Un caso de la colonización benedictina: la repoblación de Sepúlveda, en "Cistercium", 32, 1980, 205-22.

(25) Aunque el contexto sea muy diverso, no deja de evocarnos la fundación por Alfonso $X$ de Villa-Real, la Ciudad Real de hoy, en medio del Campo de Calatrava, monopolio de esta orden militar. Cf. L. R. VILLEGAS DIAZ, Algunos datos acerca de las luchas entre la Orden de Calatrava y el concejo de Villa Real en la primera mitad del siglo XIV, en el volumen colectivo aVII centenario del infante don Fernando de la Cerda. Jornadas de estudio. Abril, 1975" (Ciudad Real, 1976), pp. 179-90; y J. M. QUADRADO y V. DE LA FUENTE, Toledo y Ciudad Real ( = «España. Sus monumentos y artes, su naturaleza e historia. Castilla la Nueva», 3), pp. 447-70 (Barcelona, 1885); «no tardó en conocer Alfonso el Sabio, apenas subido al trono, que sólo una población grande y libre podla ser la custodia permanente de los caminos y el vínculo de unión entre Castilla y las ricas adquisiciones de su padre, al través de la desierta zona que los dividía. Sobre conflictos entre San Frutos y Sepúlveda, 
Y es la hora del Císter, sin embargo, también en León y Castilla la Vieja (27).

La cronología de Moreruela está controvertida, oscilando nada menos que entre 1130 y 1158 , lo que arrastraría sus pretensiones a la primacía peninsular. En todo caso se trataba de la afiliación de un monasterio preexistente, naturalmente que de benedictinos negros. En cambio, Sacramenia, en los confines de las tierras de Sepúlveda, cerca pero separada del priorato de Arlanza en Cárdaba, fue una fundación ex novo, parece que la primera de las tales a este lado de los Pirineos, en 1141. Y siguen otras, montañosas o meseteñas, según dos de los términos de la clasificación geográfica de dom Maur Cocheril. Por ejemplo, Valparaíso y Valbuena, en 1143; Huerta, en 1144; Carracedo, afiliada a Citeaux en 1203, pero con observancia cisterciense desde una data bastante anterior aunque muy discutida; Sotosalbos o Santa María de Sierra, cerca de la ciudad de Segovia, en 1212.

Monasterios cistercienses que en León y Castilla norteña, a diferencia de lo que coetáneamente estaba ocurriendo en los todavía fronterizos Portugal y Cataluña Nueva, con las enormes casas de Poblet, Santes Creus y Alcobaça, se insertan en la antes aludida repoblación meramente interior. Pero en términos inequívocos. Así, luego de la donación por Alfonso VII a Sacramenia de sus tierras en los alrededores del mismo monasterio, el 19 de febrero de 1144 (28), el rey se la confirma y a la vez la hace merced de otros derechos sobre el entorno forestal y ganadero, a 4 de junio de 1447, llamando al territorio insuper desertum (29). ¿Relevo un tanto por los benedictinos blancos de lo que ya los negros no eran tan capaces de hacer, cansados un poco de haber asumido la copiosa herencia de los tan numerosos pre-benedictinos y

M. DE LA S. MARTIN POSTIGO, San Frutos del Duratón. Historia de un priorato benedictino (Segovia, 1972).

(26) Que no se trató de un detalle aislado es el otro enclave igualmente de temprano que los benedictinos tuvieron en tierras de Sepúlveda. Documentado el año 1086 para San Millán de la Cogolla, pero ya con existencia anterior, acaso también del mismo año que el Fuero.

(27) Véase M. COCHERIL, L'implantation des abbayes cisterciennes dans la Péninsule Ibérique, en «Anuario de Estudios Medievales», 1, 1964, 217-87. También V. A. ALVAREZ PALENZUELA, Monasterios cistercienses en Castilla. Sigios X/I-XIII (Valladolid, 1978):

(28) E. CABRERA MUÑOZ, En torno a la fundación del monasterio de Sacramenia, en «La España Medieval. Estudios dedicados al profesor don Julio González González» (Madrid, 1980), pp. 31-42.

(29) R. FLETCHER, Diplomatic and the Cid revisited: the seals and mandates of Alfonso VII, en «Journal of Mediaeval History», 2, 1976, pp. 332-3 (texto del documento). 
perdido el empuje juvenil que no sólo seguía siendo necesario para avanzar más allá, sino también para consolidar la retaguardia? Quizá, aunque las excepciones no sean raras. Que ahí estaba, en 1126, el Fuero de San Frutos concedido por Alfonso VII al tal priorato y su monasterium maius de Silos, ut populetis burgum et vestram aldeiam (30). Pero en todo caso no debemos olvidarnos que también las familias religiosas tienen su biología. Y que después serian motivaciones de ésta derivadas ante todo, y no de aparentes obstáculos jurídicos, las explicativas de la ausencia monástica en la empresa americana (31), ya precedida en el mismo sentido del cuasi vacío dejado por la misma al sur del Tajo y, sobre todo, en el Guadiana y el Guadalquivir.

\section{Canónigos regulares. Premonstratenses}

Los canónigos regulares que florecen en la Iglesia a partir del siglo XI, pues en cuanto a los anteriores cualquier digresión en el plano histórico tanto como en el doctrinal seria aquí impertinente, constituyen una forma de vida intermedia entre los anteriores monjes y los posteriores frailes, la cual al no conseguir dar una respuesta a las necesidades de la nueva sociedad urbana, burguesa e itinerante bajomedieval, acabaría cediendo el paso a los últimos en esa hora de la historia.

Para la Península se pretendió que la vida canonical había predominado sobre la monástica en el Alto Medievo, tesis con la que nosotros nunca nos hemos podido mantener conformes (32).

Pero en cuanto a esta su nueva etapa que ahora nos ocupa, hemos de hacer notar que asi como en los estados orientales abundan las fundaciones nuevas o el tránsito a ellas de antiguos monasterios, en el territorio castellano-leonés, o se trata de algunas de sus congregacio-

(30) Véase el texto en el libro de Martín Postigo citado en la nota 25, núms. 2 y 3, pp. 209-12. Cf. R. HOMET, Los collazos en Castilla. Siglos X-XIV, en "Cuadernos de Historia de España», 59-60, 1976, 105-220.

(31) Salvo el caso de Brasil. Al contrario, pensando, sobre todo, en éste, los benedictinos portugueses hacían un voto suplementario llamado ultramarino. Para toda esta problemática véase nuestra comunicación El antiguo monacato en España a la hora de la implantación mendicante, en el «Encontrow citado en la nota 4.

(32) Cf. A. GARCIA GALLO, El Concilio de Coyanza, en «Anuario de Historia del Derecho Español „, 20, 1950, 275-633. Nuestra opinión en ¿Vida canonical en la repoblación de la Peninsula lbérica?, en «Secundum regulam vivere. Festchrift für $P$. Norbert Backmund, $O$. Praem., hg. von G. Melvillew (Windberg, 1978), pp. 73-85. 
nes particulares de que diremos o de la conversión a la vida común de cabildos seculares (33), aparte de haber tenido el fenómeno menos envergadura (34). Lo cual, salvo en el primer caso, más que en la implantación territorial que es nuestro argumento, se limita a incidir en la historia de las mentalidades religiosas (apostolado en la propia iglesia en lugar del enclaustramiento contemplativo).

Pero circunscribiéndonos a las tales congregaciones, nos sale al paso la de San Rufo de Aviñón, de la que había sido abad Adriano IV, papa desde 1156, respondiendo a cuyas exhortaciones Alfonso VII se la mostró generoso en su monarquía, iniciándose así su expansión leonesa (35). Otra es la de San Antón del Delfinado, que tuvo una preceptoría en Castrojeriz de la que llegaron a depender 22 casas; y sin salirse del camino de Santiago y dentro de la misma merindad de Castrojeriz, las leproserías de San Boal o Baudilio y San Antón. En fin, la también hospitalaria de Santiago de Altopascio o de los Caballeros de la Tau, poseyó en el siglo XIV en Astorga el hospital de Alto Paso, además de otra casa en Palencia (36).

Más duraderos y arraigados destinos tuvo entre nosotros Prémontré, aunque no tan esplendorosos como en otras latitudes (37), a partir de la protección que le dispensaron en la segunda mitad del siglo XII Alfonso VII y Alfonso VIII.

La precedencia de sus casas peninsulares se ha disputado entre La Vid y Retuerta, ambas junto al Duero, cerca de Aranda y Peñafiel respectivamente, fundación la primera de Domingo Gómez de Candespina, hijo de don Gómez, el favorito de la reina Urraca muerto en la batalla de Candespina, comarca de Sepúlveda, en 111, o sea, hermano ilegítimo de Alfonso VII, y antes ermitaño en el Monte Sacro, cerca de Osma; y la

(33) Así San Isidoro de León, antes monasterio de San Salvador de Palaz del Rey (desde el traslado de lós restos del Sevillano en 1063 cambiado de titularidad), cedido por doña Sancha, la hermana de Alfonso VII, a los canónigos de la catedral no conformes con pasar de monjes a seculares.

(34) Entre las fundaciones, citaremos Párraces, diócesis de Segovia, 1148; y Santa Maria, en la ciudad de Valladolid, entonces diócesis de Palencia, agustiniana por lo menos desde 1162.

(35) Estudiada por V. GARClA LOBO, La Congregación de San Rufo en el reino de León, en «Hispania Sacra», 30, 1977, 111-42.

(36) Vease P. CAUCCI, Las peregrinaciones italianas a Santiago (Santiago de Compostela, 1971), pp. 141-63.

(37) Véanse de N. BACKMUND, Monasticon Praemonstratense, III (Straubing, 1960), pp. 208-327; y el artículo pendiente de publicación en aHispania Sacra», La Orden Premonstratense en Espana. 
segunda de Sancho de Ansúrez, sobrino del conde Pedro, tan ligado a la historia de Valladolid. Mox facta est divens et potens, que de la Vid dice el padre Norberto Backmund. Ella y Retuerta se propagaron por la diócesis de Palencia y además la primera por las de Burgos, Ávila y Segovia y la segunda por la de Zamora, siendo igualmente hijas suyas San Leonardo en Alba de Tormes y La Caridad en Ciudad Rodrigo, fundación ésta de Fernando ll y el obispo Arnaldo de Coria en acción de gracias por la reconquista de Extremadura y los servicios de los mostenses en ella, como Santa Cruz de Monzón por Alfonso VIII y su empresa andaluza (38).

\section{Los mendicantes de los tiempos nuevos}

La aparición de los frailes, a diferencia de lo que había acontecido con el monacato benedictino, sorprende a la Península en una plena inserción europea (39). De ahí la trascendencia para Francisco de Asís de su estancia compostelana y el nacimiento castellano de Domingo de Caleruega.

Por eso la difusión castellanoleonesa de los mismos tiene el signo de lo común, ya de una tierra dentro de la cristiandad, sin la problemática misional de Valencia y Murcia hacia los moros incorporados o la andaluza hacia el Africa vecina que tan bien ha estudiado Robert-Ignatius Burns. Aunque esa vecindad y la Reconquista que prosigue no están ausentes de aquélla (40). Así, el fundador de la primera orden redentora, la de los trinitarios, Juan de Mata, llega a Castilla en 1206, en su segundo viaje peninsular, funda en Segovia en 1208 y su obispo Gonzalo decreta la distribución de sus ingresos en tres porciones, una para la específica redentora y dos para la caridad genérica. Pugnacidad de otrora, pero pendiente, pues, que invalida el argumento del estudioso americano James Brodman (41) para retrasar hasta 1229 la fun-

(38) Un cierto paralelismo entre las modalidades de la difusión peninsular mostense y la originaria ultrapirenaica, resulta de la lectura del artículo crítico de H. KROLL, Zum Charakter des Praemonstratenserordens in den ersten Jahrzehnten seines Bestehens, en “Analecta Praemonstratensia», 56, 1980, 21,40.

(39) Véase J. L. MARtín Rodriguez, La Península en la Edad Media (Barcelona, 1976), p. 401.

(40) Estudiado todo el tema en nuestra comunicación al aEncontrow citado en la nota 4, Algunas particularidades de la implantación mendicante en la Peninsula lberica.

(41) The origins of the Mercedarian Order: a reassesment, en «Studia Monastica», 19, 1977, 353-60. 
dación de la otra orden redentora, la Merced, por no concebirla antes de esa data de la expedición a Mallorca. La Merced que de 1290 a 1300 había fundado en Soria, Almazán y Toro, y adquirido la iglesia de San Juan en la villa segoviana de Fuentifueña, siendo ya Castilla provincia aparte en 1311.

Así las cosas, nos creemos dispensados de enumerar lugares y fechas. Baste decir de los franciscanos que Castilla ya era su provincia en 1232 (42); y que un sorprendente ejemplo de su temprana floración es la escondidísima fundación de Los Angeles o La Hoz, en el cañón del Duratón, según el cronista Francisco Gonzaga anterior a 1231. Y de los dominicos, que el propio Domingo, avistado con Fernando III en Burgos en 1218, cuando ya se había fundado la casa femenina de Madrid, primera de la Orden para monjas, se asienta allí y en Segovia, Palencia y Zamora. Mientras agustinos y carmelitas hacían acto de presencia en Castilla en el último tercio del XIII y los principios del XIV.

\section{Ordenes militares. Cartujos y jerónimos}

Las órdenes militares, a pesar de su condición religiosa y la afiliación cisterciense de casi todas, reclaman distinto tratamiento, y además su cronología aleja del territorio que nos ocupa la cuestión de su asentamiento inmediato. Bástenos con notar el nacimiento de la de Alcántara en el reino leonés; y la existencia, aunque efímera, de la de San Marcos de León, entre 1152 y 1178 o 1180, con la personificación de un puente en la ciudad, sobre el Bernesga, cual todo un síntoma de las necesidades de la nueva coyuntura (43).

En cuanto a los cartujos, respondiendo a su indole minoritaria de aristocracia espiritual, no penetran en Castilla hasta 1390, fecha de la fundación del Paular, gracias a una promesa algo novelesca de Juan I (44).

Por su parte, los jerónimos, aunque ya constituidos como cenobitas en 1374, las notas más diferenciadoras de su problemática —devotio

(42) Con 7 custodias y 44 conventos. A fines de siglo, de la provincia dominica española eran dos vicarías «Castilla con la frontera»; y León, Galicia y Portugal.

(43) D. W. LOMAX, Las milicias cistercienses en el reino de Leon, en aHispania Sacra". 23, 1963, 3-16; y J. L. MARTIN RODRIGUEZ, La Orden Militar de San Marcos de León, en ¿Qón y su historian, IV, León, 1977, pp. 19-100.

(44) L. SUAREZ FERNANDEZ, Reflexiones en torno a la fundación de San Benito de Valladolid, en aHomenaje a fray Justo Pérez de Urbel» Silos, 1977. II, pp. 433-43. 
interior, trabajo manual, conversos-y, sobre todo, la extraña exclusividad hispana de su vocación, les sitúan ya en plena modernidad. Lo mismo que a San Benito el Real de Valladolid, sin tardar mucho sede de la gran congregación benedictina de su nombre. 